\title{
Rhizosphere effect on pesticide degradation in biobeds under different hydraulic loads
}

\author{
M.C. Diez ${ }^{1,3 *}$, H. Schalchli ${ }^{1,3}$, S. Elgueta ${ }^{3}$, E. Salgado ${ }^{3}$, N. Millahueque ${ }^{3}$, O. Rubilar ${ }^{1,3}$, G.R. \\ Tortella ${ }^{3}$, G. Briceño ${ }^{3}$
}

${ }^{1}$ Chemical Engineering Department, La Frontera University, Avenida Francisco Salazar 01145, Temuco, Chile. ${ }^{2}$ Chemical and Natural Resources Department, La Frontera University, Avenida Francisco Salazar 01145, Temuco, Chile. ${ }^{3}$ Scientific and Technological Bioresource Nucleus, La Frontera University, Avenida Francisco Salazar 01145, Temuco, Chile. *Corresponding author: cristina.diez@ufrontera.cl

\begin{abstract}
Interactions between microorganisms and root exudates in a biobed system with vegetal (grass) cover could enhance pesticide degradation. Otherwise, a high water load may generate high concentrations of pesticides in lixiviates. We studied the effect of the vegetal cover on the degradation of a mixture of atrazine (ATZ), chlorpyrifos (CHL) and iprodione (IPR) (35 $\mathrm{mg} \mathrm{L}^{-1}$ each) in a biobed system operated with two different hydraulic loads ( 0.6 and $1.2 \mathrm{~L}$ of tap water per day). The concentration of the pesticides and their main metabolites were measured in the lixiviates during 60 days, as well as in the biomixtures at the end of the study. Dehydrogenase activity in the biomixtures and organic acid exudation from the vegetal cover were also analysed. The vegetal cover diminished the lixiviation of pesticides and their metabolites mainly at the lower hydraulic load used. The degradation of the pesticides was high $(>95 \%)$ and increased in biobeds with vegetal cover and low hydraulic load. Degradation metabolites of CHL and IPR were formed during pesticide degradation; however they were degraded in the biobed and were not detected in lixiviates at the end of the study. In general, an increase in organic acid exudation by vegetal cover was observed caused by chemical stress after pesticide application. The increase was similar at both hydraulic loads. Efficient colonisation of wheat straw by fungi was observed by confocal microscopy.
\end{abstract}

Keywords: Biobed, pesticide leaching, root exudates, organic acids 


\section{Introduction}

Pesticides play an important role in the success of modern farming and food production. However, residues of these compounds can be detected in different non-target sites such as soil and surface and ground water. Pesticide point source contamination has been identified as a significant contributor to deterioration in the quality of natural water resources. To minimize this problem, biobeds can be used to reduce the impact of pesticides when filling spraying equipment (Castillo et al., 2008). Since the implementation of biobeds in Sweden in 1993, this system has drawn attention in several countries, where studies are is constantly being performed to adapt it to local condition and applications. Biobeds have expanded into Latin America and the system has recently been developed in Chile with significant modifications to optimize functioning (Diez et al. 2013). Different studies have assessed the effects of operating conditions, biomixture composition, stabilization time of the biomixture, incorporation of novel lignocellulosic residues, and biomixturepesticide-microorganism interactions (Tortella et al., 2012; Urrutia et al., 2013). These results were recently reviewed by Briceño et al. (2014).

The main component of the biobed is the biomixture composed of straw, peat and soil. This composition promotes the development of different microorganisms that can degrade many pesticides and their metabolites through the production of extracellular enzymes (Castillo et al., 2008). In the biomixture, straw stimulates the growth of ligninolytic microorganisms and the production of extracellular ligninolytic enzymes such as peroxidases. Peat contributes to sorption capacity, moisture control and abiotic degradation of pesticides, and also decreases the $\mathrm{pH}$ of the biomixture, which is favourable for fungi and their pesticide-degrading enzymes (Castillo et al., 2008). Soil enhances the sorption capacity in the biobed and is an important source of pesticidedegrading bacteria that can act synergistically with the fungi. Finally, the grass layer that covers a biobed is important for enhancing the pesticide degradation efficiency especially in the upper part of the biomixture where most pesticides are retained and degraded due to interactions between microorganisms and root exudates to support co-metabolic processes (Vaughan et al., 1994). The grass layer also controls leaching, helps to keep the system humid and promotes evapotranspiration and further pesticide degradation at root level. Plant-microbial interaction increases microbial activity at the root-soil interface where physical, chemical, and/or biological parameters are modified by the presence of roots and their exudates (Anderson and Coats, 1995). The processes involved in the biotransformation of pesticides include metabolism and co-metabolism (Crowley et al., 2001). The root exudates released by plants increase microbial activity and community numbers in the rhizosphere (Chaudhry et al., 2005) and can influence the dissipation of chemicals by different pathways. In several studies, rhizodegradation is a specific type of phyto-remediation that involves both plants and their associated rhizosphere microbes; this interaction was effective for the removal and degradation of pesticides compared with unplanted soil (Anderson and Coats, 1995; Korade and Fulekar, 2009). The rhizosphere effect on the dissipation of pesticides in biobeds has been poorly studied in spite of its positive effect (Debaer and Jaeken, 2006). Recently, the effect of plants such as Lolium perenne, Festuca arundinacea and Trifolium repens in a biobed system was evaluated by Urrutia (2014), one of the few studies of this subject. 
Like any pesticide treatment system, biobeds must be able to treat a complex mixture of pesticides, applied repeatedly and often at high concentrations (Fogg et al., 2004; Tortella et al., 2013). Biobed performance related with water management is crucial for improving pesticide removal efficiency. Fogg et al. (2004) showed that pesticide leaching potential was affected by hydraulic load. Therefore, high water loads soon after the application of pesticides could generate insufficient contact time between the pesticides and the biomixture and may result in the appearance of pesticides in leachate. The aim of this study was to study the effect of vegetal cover in a biobed system operated with two hydraulic loads on the degradation of a mixture of pesticides and their metabolites.

\section{Material and Methods}

\subsection{Chemicals}

Formulated chlorpyrifos CHL, (Clorpyrifos S480), iprodione (IPR, Rovral 4FLO) and atrazine ATZ, Atranex $50 \mathrm{SC}$ ) were purchased from Agan Chemicals Manufacturers Ltd. The analytical standards 2-hydroxyatrazine (HA, 98\%), 3,5-dichloroaniline (2,5 DCA, 99.7\%) and 3,5,6-trichloro-2-pyridinol (TCP, 99.3\%) were purchased from Sigma-Aldrich (St. Louis, MO). Floricil was purchased from JT Baker and the organic acids were purchased from Merck International.

\subsection{Biomixture formulation}

The biomixture was prepared mixing an Andisol topsoil (37\% sand, $34 \%$ silt, $28 \%$ clay, $7 \%$ organic carbon, $\mathrm{pH} 5.4$ ), commercial peat (36\% organic carbon), and wheat straw (34\% organic carbon), in a proportion of 1:1:2 by volume, respectively. The soil, which belonged to the Freire series (38 $50^{\circ}$ 'S, $\left.72^{\circ} 41^{\prime} \mathrm{W}\right)$ at Maquehue Experimental Station of Universidad de La Frontera in southern Chile, was collected at a depth of 0 to $20 \mathrm{~cm}$, air-dried at room temperature and sieved through a $2 \mathrm{~mm}$ mesh. The straw was collected from crop residues in a local farm and was chopped to obtain fractions of 5 to $10 \mathrm{~cm}$ length. The constituents were mixed vigorously to obtain a homogeneous biomixture; this biomixture, with $60 \%$ of water holding capacity (WHC), was placed on the ground, covered with plastic to avoid the effects of rain, and left to compost for 60 days until use. The resulting biomixture had $\mathrm{pH} 5.5,33 \%$ organic carbon and $0.6 \%$ total nitrogen.

\subsection{Biobed operation conditions and assay setup}

The biopurification system was installed using plastic containers of $1 \mathrm{~m}^{3}(100 \times 100 \times 100 \mathrm{~cm}$ length, width and height) with the bottom sealed and with a pipe installed from the bottom to a height of $15 \mathrm{~cm}$ to collect lixiviates. A layer of gravel about $20 \mathrm{~cm}$ in depth was placed at the bottom of the containers and covered with a semi-porous geomembrane to allow lixiviates to leach down to the collection point. Each container was packed with $125 \mathrm{~kg}$ of biomixture (bulk density ( $\rho) 0.29 \mathrm{~g} \mathrm{~mL}^{-1}$ ), to a height of $60 \mathrm{~cm}$. The assay included four treatments divided as follows: two containers with biomixture plus vegetal cover plus pesticide mixture (L1), two containers with biomixture plus pesticide mixture without vegetal cover (L2), two containers with biomixture plus vegetal cover without pesticide mixture (L3) and two containers biomixture without plants and without pesticide mixture (L4). For planted containers, a thin layer of soil $(5 \mathrm{~cm})$ was placed on top of the biomixture and then a commercial vegetal cover (mixture of Festuca sp. and perenne) was installed and kept wet by addition of tap water during 15 days to allow the roots to penetrate into the biomixture. 
The vegetation cover was then cut leaving a plant height of $5 \mathrm{~cm}$. After contamination, the biomixture of each container was maintained at $50-60 \%$ of water holding capacity (WHC). A water solution (484 mg $\mathrm{L}^{-1}$ ) containing a mixture of formulated ATZ, CHL and IPR (35 mg of each active ingredient (a.i.) $\mathrm{kg}^{-1}$ of biomixture) was prepared and sprayed over the surface of four containers (L1 and L2), while the other four (L3 and L4) remained as control without pesticide contamination. One set of four containers (one of each treatment) was treated with a hydraulic load of $0.6 \mathrm{~L}$ $\mathrm{d}^{-1}$ of tap water and the other with a hydraulic load of $1.2 \mathrm{~L} \mathrm{~d}^{-1}$ of tap water, during a period of 60 days. The assay was kept under field conditions at room temperature and the containers were installed beneath a roof for protection against rain.

Lixiviate samples were taken from each container and analysed for pesticides and their metabolites at 0,15 , 30, 45 and 60 days. Dehydrogenase analysis was done in the biomixture by taking samples from the first 15 $\mathrm{cm}$ below the vegetal cover of each container at 0,15 , 30,45 and 60 days. Organic acids were analysed at 0 , $5,15,30,45$ and 60 days from the vegetal cover, by extracting representative samples of $50 \times 50 \mathrm{~mm}$ with a knife, ensuring that the roots were not affected or severed. Organic acids were extracted and measured by high-performance liquid chromatography (HPLC).

\subsection{Analysis}

The dehydrogenase activity was determined using the methodology proposed by Casida (1977). Moist biomixture (equivalent to $2 \mathrm{~g}$ dry weight) was incubated for $24 \mathrm{~h}$ at $37{ }^{\circ} \mathrm{C}$ with $4 \mathrm{~mL}$ of buffer Tris (pH 6) and $2 \mathrm{~mL}$ of $1 \%$ 2,3,5 triphenyl tetrasolium chloride (TTC) as a substrate. After incubation, 10 $\mathrm{mL}$ of methanol was added and tubes were vigorously agitated to extract the reaction product triphenyl formasan (TPF). The pink liquid was centrifuged at
4,500 rpm for $10 \mathrm{~min}$ at $4{ }^{\circ} \mathrm{C}$. TPF concentration was measured at $485 \mathrm{~nm}$ and dehydrogenase activity was expressed as $\mu \mathrm{g}$ TPF $\mathrm{g}^{-1}$ dry biomixture $\mathrm{h}^{-1}$.

For the analyses of pesticides and their metabolites, biomixture samples ( $5 \mathrm{~g}$ dry weight) were extracted by shaking for ( $1 \mathrm{~h}$ at $250 \mathrm{rpm}$ ) with $20 \mathrm{~mL}$ of acetone and by ultrasonication (30 $\mathrm{min})$. After centrifuging $(10,000 \mathrm{rpm}), 5 \mathrm{~mL}$ of the supernatant was collected, filtered through a PTFE membrane $(0.2 \mu \mathrm{m}$ pore size) and evaporated to dryness under an $\mathrm{N}_{2}$ flow, after which the residue was dissolved with $1 \mathrm{~mL}$ of acetonitrile and subsequently analysed as described below. Recovery of ATZ, CHL and IPR was $>85 \%$. The pesticide concentrations were determined by HPLC using a Merck Hitachi L-2130 pump equipped with a Rheodyne 7725 injector with a $20 \mu \mathrm{L}$ loop and a Merck Hitachi L-2455 diode array detector. Separation was achieved using a C18 column (Chromolit RP-8e, $\mu \mathrm{m} 4.6 \times 100 \mathrm{~mm}$ ). Eluent A was $1 \mathrm{mM}$ ammonium acetate and eluent $\mathrm{B}$ was acetonitrile. The gradient conditions used for pesticide separation was as follows: $\min 0-2,95 \% \mathrm{~A}$; $\min 2-4,95-70 \%$ A; $\min 4-7,70 \% \mathrm{~A}$; $\min 7-12,70-30 \% \mathrm{~A}$; $\min 12-16$ $30 \% \mathrm{~A}$; $\min 16-17,30-95 \% \mathrm{~A}$; and $\min 17-20,95 \%$ A. The flow rate was set as follows: $\min 0-12$ at $1 \mathrm{~mL}$ $\mathrm{min}^{-1}$, min 12-16 at 1-2 $\mathrm{mL} \mathrm{min}^{-1}$, increasing during $\min 16-20$ to $2 \mathrm{~mL} \mathrm{~min}^{-1}$. The column temperature was maintained at $30 \pm 1{ }^{\circ} \mathrm{C}$. The detector was set at 3 wavelengths for data acquisition: 220, 245 and 290 $\mathrm{nm}$. Instrument calibrations and quantifications were performed against pure reference standards (0.1-10 $\mathrm{mg} \mathrm{L}^{-1}$ ) for each compound.

For organic acid analyses, roots from the vegetal cover were washed with distilled water and then placed in $50 \mathrm{~mL}$ of distilled water for $30 \mathrm{~min} ; 5 \mathrm{~mL}$ were filtered through a PTFE membrane $(0.2-\mu \mathrm{m}$ pore size, Millipore), and the organic acid concentration was determined by HPLC. Root exudates were standardized by root dry weight, which was measured 
immediately after treatment. Oxalic acid, malic acid, citric acid and succinic acid concentrations were determined by HPLC using a Merck Hitachi L-7100 pump, a Rheodyne 7725 injector with a $20 \mu \mathrm{L}$ loop and a Merck Hitachi L-7455 diode array detector. Separation was performed using a C18 column (Purospher Star RP-C18e, $5 \mu \mathrm{m} 4.6 \times 150 \mathrm{~mm}$ ) with a guard column (LichroCART RP-C18e, $5 \mu \mathrm{m} 4$ x 4 mm). Eluent A was methanol, and eluent $\mathrm{B}$ was phosphate buffer. The gradient condition used for organic acid separation was $\min 0-15,7 \% \mathrm{~A}$. The flow rate for $\min 0-15$ was set at $1.0 \mathrm{~mL} \mathrm{~min}{ }^{-1}$. The column temperature was maintained at $30 \pm 1^{\circ} \mathrm{C}$. The detector was set at $210 \mathrm{~nm}$ for data acquisition. Instrument calibrations and quantifications were performed against pure reference standards (0.1-10 $\left.\mathrm{mg} \mathrm{L}^{-1}\right)$ for each compound. Recovery of each organic acid was $>90 \%$.

For confocal laser scanning microscopy, samples of wheat straw (WS) at day 1 and wheat straw obtained from the biomixture of the different treatments (L1, L2, L3 and L4) after 60 days of operation were observed under confocal laser scanning microscopy (CLSM). Samples 0-20 cm deep were stained sequentially with $0.1 \%$ Safranin O and $0.1 \%$ Calcofluor for $20 \mathrm{~min}$ and washed with distilled water at $30{ }^{\circ} \mathrm{C}$ and viewed in Fluoview FV1000 (Olympus, Japan) Confocal Laser Scanning Microscope (CLSM). The CLSM images were captured by exciting the stained samples at 488 and $543 \mathrm{~nm}$.

\section{Results and Discussion}

The pesticides ATZ, IPR and the metabolite TCP were found at low concentration $(<0.5 \mathrm{mg}$ $\mathrm{L}^{-1}$ ) in lixiviates of the biobeds with and without vegetal cover at the two hydraulic loads used. The metabolite of ATZ, ( HA) IPR (3,5 DCA) and CHL were not detected in lixiviates throughout the study at both hydraulic loads used (Figure 1A and B). The level of ATZ in lixiviates of biobeds declined with time and lower concentrations were found in biobeds with vegetal cover at both hydraulic loads. The highest ATZ concentrations in lixiviates of biobeds with and without vegetal cover at hydraulic load of $0.6 \mathrm{~L} \mathrm{~d}^{-1}$ were 0.23 and $0.47 \mathrm{mg} \mathrm{L}^{-1}$ at day 0 , respectively (Figure $1 \mathrm{~A}$ ). These values represent very low quantities considering that the initial concentration of pesticides added to each biobed was $484 \mathrm{mg} \mathrm{L}^{-1}$. Furthermore, there was no difference in ATZ concentration $\left(0.05 \mathrm{mg} \mathrm{L}^{-1}\right)$ in lixiviates of biobeds with vegetal cover at the two hydraulic loads after 60 days of operation. In biobeds without vegetal cover by contrast, ATZ concentrations in lixiviates were 0.16 at $0.6 \mathrm{~L} \mathrm{~d}^{-1}$ and $0.11 \mathrm{mg} \mathrm{L}^{-1}$ at $1.2 \mathrm{~L} \mathrm{~d}^{-1}$ after 60 days of operation. Studies have reported that ATZ is highly degraded in biobeds, with degradation of about $90 \%$ after 60 days (Diez et al., 2013; Tortella et al., 2013). In addition, HA, the main metabolite of ATZ degradation, was not found in lixiviates of all treatments due to its low water solubility $\left(5.90 \mathrm{mg} \mathrm{L}^{-1}\right)$; the adsorption process may therefore be favoured in the biomixtures. Biological activity is responsible for most ATZ degradation, while low molecular weight organic acids could reduce adsorption and promote desorption of some pesticides in water (Hunter and Shaner, 2009) and in soils (Ding et al., 2011).

The CHL pesticide was not detected in lixiviates; this result is largely associated with the high affinity that CHL has with the organic components of this type of biomixture. Fernández et al. (2012) reported Koc value of CHL of 11390 in a similar biomixture and 7079 in soil belonging to the Freire series. By contrast TCP, the main metabolite of $\mathrm{CHL}$ degradation, was found in concentrations between 0.04 and $0.28 \mathrm{mg} \mathrm{L}^{-1}$ in the different treatments evaluated. When a hydraulic load of $0.6 \mathrm{~L} \mathrm{~d}^{-1}$ was applied, the TCP concentration was very low $\left(0.04 \mathrm{mg} \mathrm{L}^{-1}\right)$ after 5 and 15 days of operation in a biobed with vegetal cover. In a biobed without vegetal cover however, TCP was detected until day 30 
with a maximum of $0.13 \mathrm{mg} \mathrm{L}^{-1}$ at day 15 (Figure 1A). On the other hand, when a hydraulic load of $1.2 \mathrm{~L} \mathrm{~d}^{-1}$ was applied, the TCP concentration increased until day 15 when the highest concentration of TCP was obtained ( $\left.0.28 \mathrm{mg} \mathrm{L}^{-1}\right)$; thereafter it declined and was not found by the end of the study (Figure 1B). No difference was found between the biobeds with and without vegetal cover at this hydraulic load. This result could be explained by their greater solubility $\left(80.9 \mathrm{mg} \mathrm{L}^{-1}\right)$ compared with CHL (1.4 $\mathrm{mg} \mathrm{L}^{-1}$ ). The absence of CHL in lixiviates and the formation of TCP in all treatments indicate that CHL was degraded in this biobed system. Several studies have demonstrated that $\mathrm{CHL}$ can be dissipated efficiently $(>75 \%)$ in biobed biomixtures; materials with an active lignin-degrading microflora are a condition for effective dissipation and non-accumulation of TCP (Coppola et al., 2007; Fernández et al., 2012; Tortella et al., 2012). The concentrations of IPR detected in the lixiviates varied between 0.03 and $0.34 \mathrm{mg} \mathrm{L}^{-1}$ in the different treatments evaluated. In general, IPR concentrations were lower in biobeds with vegetal cover at the two hydraulic loads applied and no IPR was detected in lixiviates after 60 days of operation. The highest IPR concentration $\left(0.34 \mathrm{mg} \mathrm{L}^{-1}\right)$ was obtained in the first five days of operation of the biobed without vegetal cover and $1.2 \mathrm{~L} \mathrm{~d}^{-1}$ hydraulic load. These results agree with reports that indicate that IPR is a pesticide found frequently in drainage water (Strömqvist and Jarvis, 2005) after pesticide application in the field.

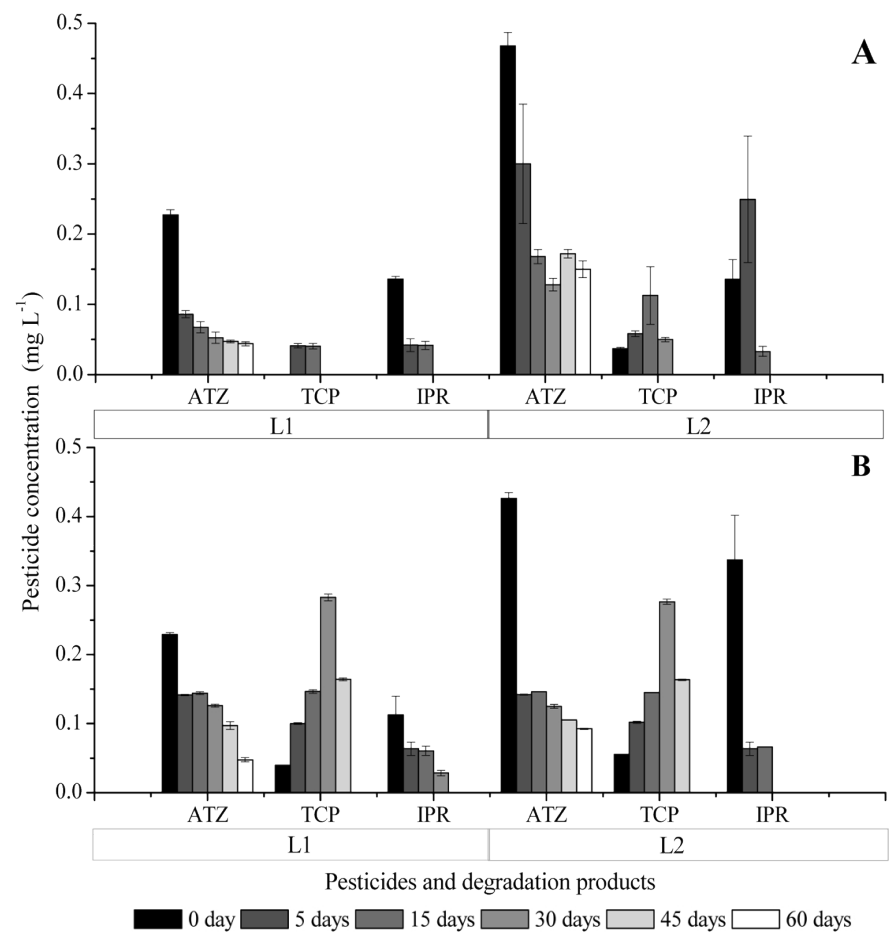

Figure 1. Concentration of pesticides and their metabolites in lixiviates from biobeds contaminated with a mixture of atrazine (ATZ), chlorpyrifos (CHL) and iprodione (IPR) at initial $35 \mathrm{mg} \mathrm{kg}^{-1}$ concentration. L1, biobed with vegetal cover and L2, biobed without vegetal cover. Hydraulic load of $0.6 \mathrm{~L} \mathrm{~d}^{-1}(\mathbf{A})$ and $1.2 \mathrm{~L} \mathrm{~d}^{-1}(\mathbf{B})$. Data are expressed as mean \pm standard error The products 2-hydroxyatrazine (HA), CHL and 3,5-dichloroaniline (3,5 DCA) were not included in the Figure since they were not detected in the sample. 
At the end of the study, residual pesticides and their main metabolites in the biomixtures of biobeds with and without vegetal cover were measured. All three pesticides and their metabolites were found at low concentration ( $<4.5 \mathrm{mg} \mathrm{L}^{-1}$ ) in the biomixtures, except for HA (Figure 2). The residual ATZ concentration was two times lower at hydraulic load $0.6 \mathrm{~L} \mathrm{~d}^{-1}\left(0.075 \mathrm{mg} \mathrm{L}^{-1}\right)$ than at hydraulic load at $1.2 \mathrm{~L} \mathrm{~d}^{-1}\left(1.7 \mathrm{mg} \mathrm{L}^{-1}\right)$ in biomixtures with vegetal cover. However, similar residual ATZ concentration (approx. $2.0 \mathrm{mg} \mathrm{L}^{-1}$ ) was found in biomixtures without vegetal cover at the two hydraulic loads used. The HA metabolite was not found either in the lixiviate assay or in the biomixtures, indicating that probably the HA concentration was below their limit of detection, or that ATZ degradation was not by the dehalogenation pathway. Residual CHL was several times lower in biomixtures with vegetal cover (L1) than in biomixtures without vegetal cover (L2). The CHL concentration was similar in biomixtures with vegetal cover at the two hydraulic loads used (approx. $0.35 \mathrm{mg} \mathrm{L}^{-1}$ ). On the other hand, in biomixtures without vegetal cover the CHL concentration was 2.5 times lower at $1.2 \mathrm{~L} \mathrm{~d}^{-1}$ hydraulic load, due to greater dissolution of the $\mathrm{CHL}$ at this hydraulic load. Biological activities and organic acid exudation collaborate with $\mathrm{CHL}$ degradation; therefore a higher quantity of TCP was quantified in biomixtures with vegetal cover. On the other hand, the TCP concentration decreased in biobed biomixtures without vegetal cover mainly when the water load of $0.6 \mathrm{~L} \mathrm{~d}^{-1}$ was added. IPR was detected only in biomixtures with vegetal cover; its concentration was lower at $1.2 \mathrm{~L} \mathrm{~d}^{-1}$. The concentration of 3,5 DCA metabolite was higher in biomixtures with vegetal cover at a hydraulic load of $0.6 \mathrm{~L} \mathrm{~d}^{-1}$; a similar concentration (approx. $2.5 \mathrm{mg} \mathrm{L}^{-1}$ ) was quantified in biomixtures with and without vegetal cover at $1.2 \mathrm{~L} \mathrm{~d}^{-1}$. The formation of degradation products of the pesticides studied confirms their degradation in this type of biomixture, as has been reported in the literature (Tortella et al., 2012; Fernández et al., 2012; Urrutia et al., 2013).
In general, ATR and CHL dissipation increased in biobeds with vegetal cover, compared with biobeds without vegetal cover. Otherwise, the hydraulic load influences the behaviour of the pesticides and their metabolites in the lixiviates of the biobeds; however it was not directly associated with effects on pesticide concentration and degradation in the biomixture. Similarly Fogg et al. (2004) reported that pesticides lixiviated from biobeds are controlled by the amount of water passing through the system.

Dehydrogenase activity (Figure 3) in the biomixtures contaminated with the pesticide mixture was analysed because dehydrogenase is the enzyme used as an indicator of overall microbial activity. The results showed that dehydrogenase activity increased after 5 days in all treatments $\left(>16 \mu \mathrm{g} \mathrm{TPF} \mathrm{gh}^{-1}\right)$ showing a tendency towards

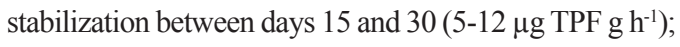
activity in the biomixture increases again after 40 and 60 days of operation (22-30 $\mu \mathrm{g} \mathrm{TPF} \mathrm{g} \mathrm{h}^{-1}$ ), coinciding with the trend observed in biobed systems (Tortella et al., 2013). At the end of the assay, dehydrogenase activity in biomixture with vegetal cover without pesticides (L3) showed the highest concentration at both hydraulic loads tested; its activity decreased in biomixtures with pesticide application due to some toxicity effect of the pesticides and their metabolites. Otherwise, in biobeds treated with $0.6 \mathrm{~L} \mathrm{~d}^{-1}$ and without vegetal cover and without pesticide application (L4), dehydrogenase activity showed lower values than those observed in treatments L1, L2 and L3, which could be explained by the contribution of the vegetal cover in keeping the moisture in the system, in addition to the beneficial effect of the interaction between plants and microorganisms due to the exudation of organic acids (Shi et al., 2011; Wang et al., 2014). Plants increase or improve root exudation under chemical stress, which increases microbial activity and community numbers thus enhancing the degradation of pollutants (Chaudhry et al., 2005); this could explain the lower concentrations of ATR and CHL found in biomixture with vegetal cover. 


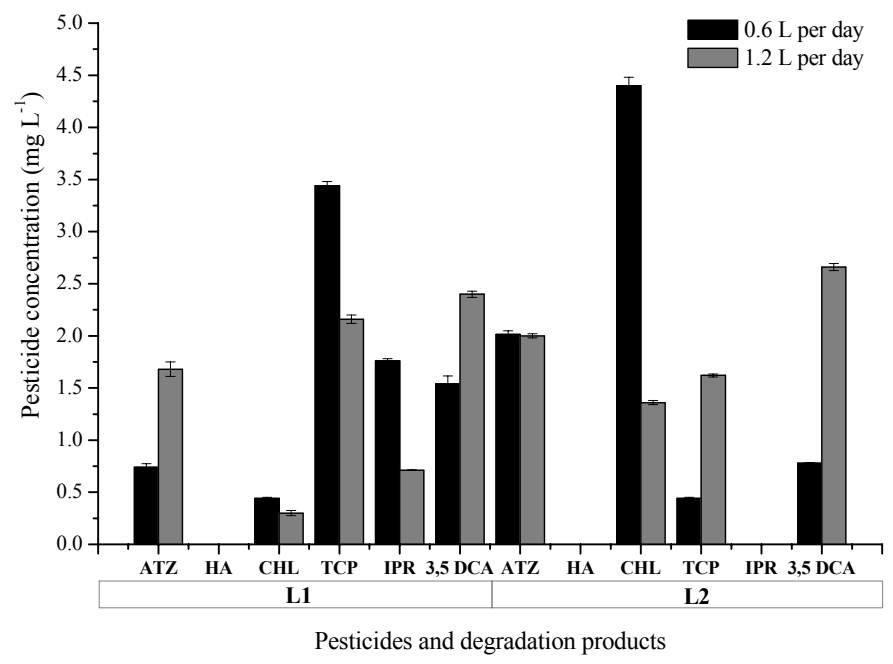

Figure 2. Concentration of pesticides and their metabolites in the biomixture of biobeds contaminated with a mixture of atrazine (ATZ), chlorpyrifos (CHL) and iprodione (IPR) at initial $35 \mathrm{mg} \mathrm{kg}^{-1}$ concentration. L1, biobed with vegetal cover and L2, biobed without vegetal cover. Hydraulic load of $0.6 \mathrm{~L} \mathrm{~d}^{-1}(\mathbf{A})$ and $1.2 \mathrm{~L} \mathrm{~d}^{-1}(\mathbf{B})$. Samples were taken after 60 days of operation. Data are expressed as mean \pm standard error.

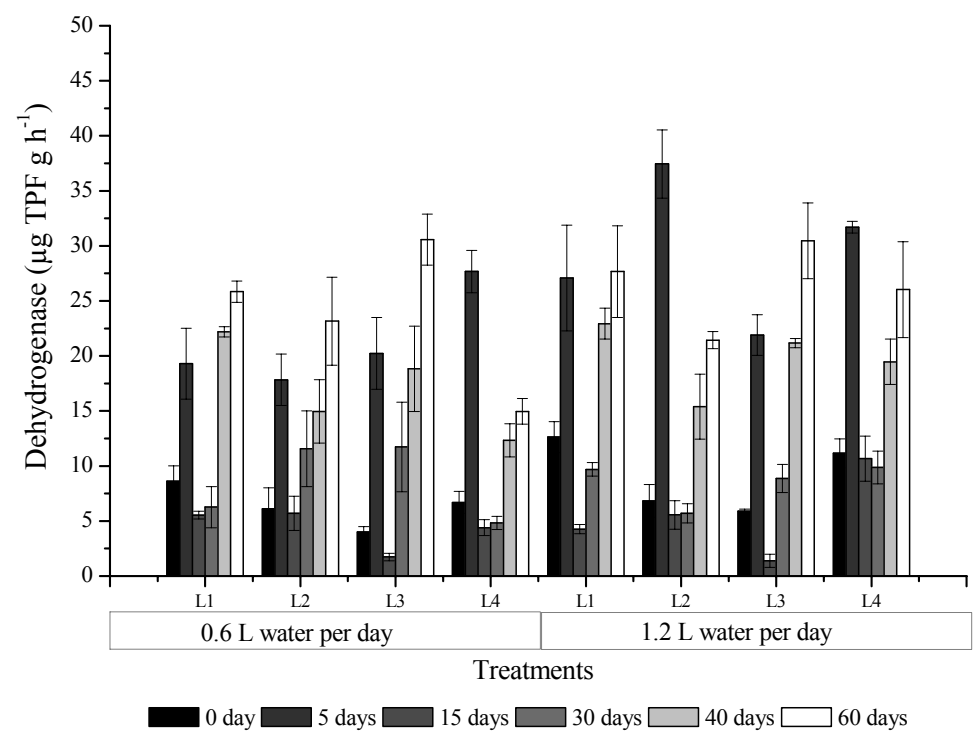

Figure 3. Dehydrogenase activity in biomixtures with two hydraulic loads of tap water $\left(0.6\right.$ and $\left.1.2 \mathrm{~L} \mathrm{~d}^{-1}\right)$. Samples were obtained at 0-10 $\mathrm{cm}$ depth during 60 days. L1, biobed with pesticide mixture and vegetal cover; L2, biobed with pesticide mixture without vegetal cover; L3, biobed with vegetal cover without pesticide mixture and L4, biobed in the absence of both pesticide mixture and vegetal cover. 
The results of the analyses of organic acid exudation from the vegetal cover of biobeds showed a high concentration of oxalic acid (up to $5 \mathrm{mg} \mathrm{L}^{-1}$ ) and smaller amounts of citric, malic and succinic acid $(<$ $2.5 \mathrm{mg} \mathrm{L}^{-1}$ ) in both hydraulic loads used. Oxalic acid production was highest in the biomixture with vegetal cover (L1) using both 0.6 and 1.2 L of hydraulic load. In general, an increase in oxalic acid production was observed after pesticide application, probably caused by a chemical stress in the plants after the application of pesticide. In all treatments, these values decreased to approximately $1.1 \mathrm{mg} \mathrm{L}^{-1}$ between days 15 and 45 . A similar tendency was observed in the concentration of citric acid, where about $1.2 \mathrm{mg} \mathrm{L}^{-1}$ was detected in treatment $\mathrm{L} 1$ at day 45 with $1.2 \mathrm{~L} \mathrm{~d}^{-1}$ of hydraulic load. This value showed a marked difference in relation to L3 at the same hydraulic load. Malic acid concentration was highest after 45 days of biobed operation and at $1.2 \mathrm{~L} \mathrm{~d}^{-1}$ hydraulic load. Finally, low concentrations of succinic acid were detected ( 0 to $\left.0.75 \mathrm{mg} \mathrm{L}^{-1}\right)$; the treatments with the highest succinic acid concentrations were L1 at days 5 and 45 with a hydraulic load of $1.2 \mathrm{~L} \mathrm{~d}^{-1}$. The effect of the hydraulic load and pesticide application on the concentration of organic acids extracted from the rhizosphere showed no clear trend, except in the behaviour of oxalic acid. In general, plants increase or improve root exudation under chemical stress because they increase microbial activity and community numbers, enhancing the degradation of pollutants (Chaudhry et al., 2005). Low concentrations of organic acids detected during the intermediate days of the trial (days 15-45) could be related to the formation of degradation products of the pesticides such as TCP, which was found in greater amounts during this period. Therefore, we suggest that changes in the level of the initial concentration of pesticides and/or the formation of their degradation products influenced the production of organic acids, mainly succinic acid. Wang et al. (2014) showed that organic acids as well as dehydrogenase activity in the rhizosphere change with the contamination level of polycyclic aromatic hydrocarbon, concluding that succinic acid and dehydrogenase activity enhance the removal of the contaminants tested.

To evaluate fungal colonization of the straw in the biomixture, we used confocal microscopy to obtain a series of optical sections from stained samples during pesticide degradation. Samples of wheat straw (WS) from the biomixture were stained with calcofluor and safranin $\mathrm{O}$ to observe fungal mycelia (blue) and lignin fluorescence (green). Figure 5A represents a wheat straw sample without any initial treatment and we can observe negligible colonisation by fungi (blue) and great fluorescence from intact lignin (green). Figure 5B, $\mathrm{C}, \mathrm{D}$ and $\mathrm{E}$ show WS of the biomixtures with different treatments after 60 days of incubation. In general, lignin degradation by fungal attack can be observed from the significant decrease in its fluorescence. Figure 5B represents a WS sample taken from the control biomixture (L4), in which we observe an increment in lignin colonisation and degradation by fungi present in the biomixture. In Figure 5C, we observe strong colonisation of lignin by fungi and hyphae on and into the lignin in the biomixture with plant cover (L3). Considerable degradation of lignin by fungi in several points of the wheat straw is demonstrated by the low fluorescence observed. In Figure 5D a small amount of mycelium is observed but with thicker hyphae, probably due to the influence of the pesticides in this biomixture (L2). The degradation of the lignin in the L2 biomixture is located near the fungal hyphae where the fluorescence decreases. Finally, Figure 5E shows inter and intra cellular colonisation of wheat straw by fungi at a great intensity as well as lignin degradation in the L1 biomixture. In general, no variation of WS colonisation by fungi was observed between the two hydraulic loads employed in the study. 

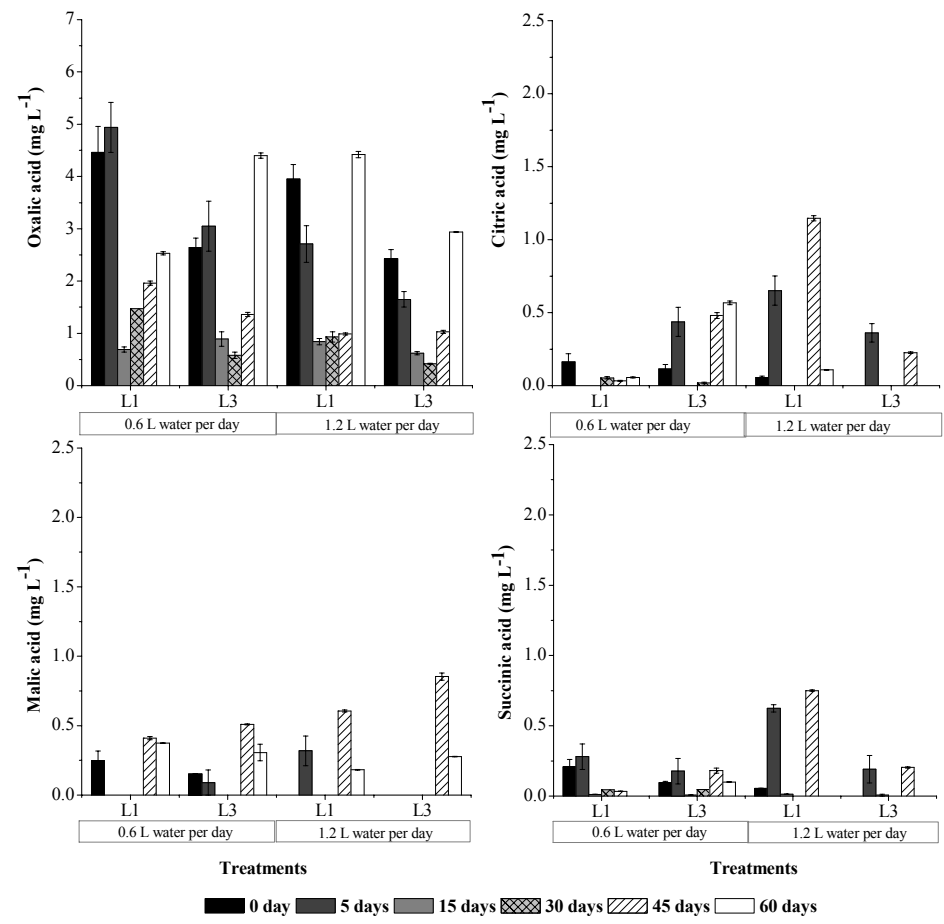

Figure 4. Concentration of organic acids extracted from the rhizosphere of the biobeds with two hydraulic loads of tap water ( 0.6 and $\left.1.2 \mathrm{~L} \mathrm{~d}^{-1}\right)$. L1, biobed with vegetal cover and pesticide mixture and L3, biobed with vegetal cover without pesticide mixture. The samples were analysed during 60 days and the initial concentration of each pesticide was $35 \mathrm{mg} \mathrm{kg}^{-1}$. Data are expressed as mean \pm standard error.
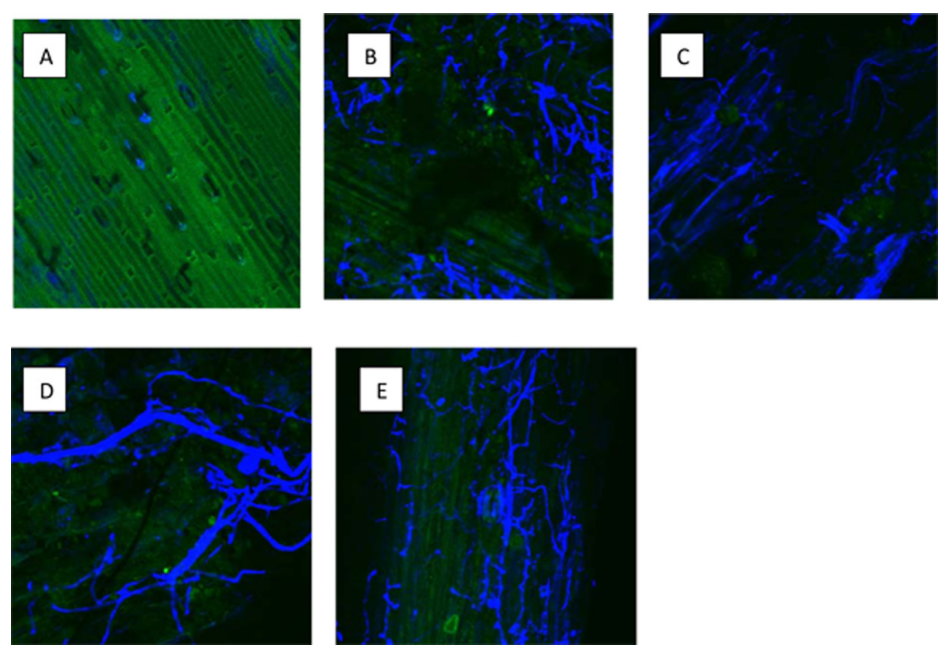

Figure 5. Confocal laser scanning micrographs of wheat straw from biomixture of biobeds. A, wheat straw at start time (day 0); B, wheat straw from L4 biomixture; C, wheat straw from L3 biomixture; D, wheat Straw from L2 biomixture and E, wheat straw from L1 biomixture. Micrographs B, C, D and $\mathbf{E}$ were taken after 60 days of operation. 


\section{Conclusions}

The vegetal cover diminished lixiviation of pesticides and their metabolites, particularly at lower hydraulic load. Pesticide degradation was high (>95\%) increasing in biobeds with vegetal cover due to interactions between the biomixture and rhizospheric microorganisms, and at low hydraulic load. TCP and DCA metabolites were formed during pesticide degradation, but they were degraded in the biobeds and were not detected in lixiviates at the end of the study. The highest exudation of organic acid by the vegetal cover was oxalic acid exudation in the biobed contaminated with the pesticides; it was similar at both hydraulic loads. Finally, efficient colonisation of wheat straw by fungi was observed by confocal microscopy.

\section{Acknowledgments}

This work was supported by FONDECYT project $\mathrm{N}^{\mathrm{o}}$ 1120963 and CONICYT/FONDAP/15130015. GAP UFRO.

\section{References}

Anderson, T.A., Coats, J.R. 1995. Screening rhizosphere soil samples for the ability to mineralize elevated concentrations of atrazine and metolachlor. J. Environ. Sci. Heal. B. 30, 473-84.

Briceño, G., Tortella, G., Rubilar, O., Palma, G., Diez, M.C. 2014. Advances in Chile for the treatment of pesticide residues: Biobeds technology. In: A. Alvarez., M. Polti (Ed). Bioremediation in Latin America. Current research and perspectives. Springer Cham Heidelber New York Dordrecht London, pp: 53-68.

Casida, L.E. 1977. Microbial metabolic activity in soil as measured by dehydrogenase determinations. Appl. Environ. Microbiol. 34(6), 630-636.
Castillo, MdP., Torstensson, L., Stenström, J. 2008. Biobeds for environmental protection from pesticide uses, a review. J. Agric. Food Chem. 56, 6206-6219.

Coppola, L., Castillo, M.P., Monaci, E., Vischetti, C. 2007. Adaptation of the biobed composition for chlorpyrifos degradation to southern Europe conditions. J. Agr. Food Chem. 55, 396-401.

Chaudhry, Q., Blom-Zandstra, M., Gupta, S., Joner, E. 2005. Utilising the synergy between plants and rhizosphere microorganisms to enhance breakdown of organic pollutants in the environment. Environ. Sci. Pollut. Res. 12, 34-48.

Crowley, D.E., Luepromechai, E., Singer, A. 2001. Metabolism of xenobiotics in the rhizosphere. In: J.C. Hall, R.E. Hoagland, and R.M. Zablotowicz (Ed). Pesticide Biotransformation in Plants and Microorganisms: Similarities and Divergences. ACS Symposium Series 777. Washington, DC: American Chemical Society, pp: 333-352.

Debaer, C., Jaeken, J. 2006. Modified bio filters to clean up leftovers from spray loading and cleaning; experience from pilot installations. Asp. Appl. Biol. 77, 247-252.

Diez, M.C., Tortella, G.R., Briceño, G., Castillo, MdP., Díaz, J., Palma, G., Altamirano, C., Calderón, C., Rubilar, O. 2013. Influence of novel lignocellulosic residues in a biobed biopurification system on the degradation of pesticides applied in repeatedly high doses. Electron. J. Biotechnol. 16, 1-11.

Ding, Q., Wu, H.L., Xu, Y., Guo, L.J., Liu, K., Gao, H.M., Yang, H. 2011. Impact of low molecular weight organic acids and dissolved organic matter on sorption and mobility of isoproturon in two soils. J. Hazard. Mater. 190, 823-832.

Fernández, S., Rubilar, O., Tortella, G.R., Diez, M.C. 2012. Chlorpyrifos degradation in a Biomix: Effect of pre-incubation and water holding capacity. J.Soil Sci. Plant Nutr. 12, 785-799. 
Fogg, P., Boxall, A.B.A., Walker, A., Jukes, A. 2004 Leaching of pesticides from biobeds: Effect of biobed depth and water loading. J. Agric. Food Chem. 52, 6217-6227.

Hunter, W.J., Shaner, D.L. 2009. Nitrogen limited biobarriers remove atrazine from contaminated water: laboratory studies. J. Contam. Hydrol. 103, 29-37.

Korade, D.L., Fulekar, M.H. 2009. Rhizosphere remediation of chlorpyrifos in mycorrhizospheric soil using ryegrass. J. Hazard. Mater. 172, 13441350 .

Shi, S., Richardson, A.E., O'Callaghan, M., DeAngelis, K.M., Jones, E.E., Stewart, A., Firestone, M.K., Condron, L.M. 2011. Effects of selected root exudate components on soil bacterial communities. FEMS Microbiol. Ecol.77, 600-610.

Strömqvist, J., Jarvis, N. 2005. Sorption, degradation and leaching of the fungicide iprodione in a golf green under Scandinavian conditions: measurements, modelling and risk assessment. Pest. Manag. Sci. 61, 1168-1178.

Tortella, G.R., Rubilar, O., Castillo, M.d.P., Cea, M., Mella-Herrera, R., Diez, M.C. 2012. Chlorpyrifos degradation in a biomixture of biobed at different maturity stages. Chemosphere. 88, 224-228
Tortella, G.R., Mella-Herrera, R.A., Sousa, D.Z., Rubilar, O., Acuña, J.J. Briceño , G., Diez, M.C. 2013. Atrazine dissipation and its impact on the microbial communities and community level physiological profiles in a microcosm simulating the biomixture of on-farm biopurification system. J. Hazard. Mater. 260, 459-467.

Urrutia, C., Rubilar, O., Tortella, G.R., Diez, M.C 2013. Degradation of pesticide mixture on modified matrix of a biopurification system with alternatives lignocellulosic wastes. Chemosphere. 92, 1361-1366.

Urrutia, C. 2014. Rhizosphere effect on the dissipation of pesticides in a biobed system. Doctoral thesis. Programa de Doctorado en Ciencias de Recursos Naturales. Universidad de La Frontera, TemucoChile.

Vaughan, D.; Cheshire, M.V.; Ord, B.G. 1994. Exudation of peroxidase from roots of Festuca rubra and its effects on exuded phenolic acids. Plant and Soil. 160, 153-155.

Wang, Y., Fang, L., Lin, L., Luan, T., Tam, N. 2014 Effects of low molecular-weight organic acids and dehydrogenase activity in rhizosphere sediments of mangrove plants on phytoremediation of polycyclic aromatic hydrocarbons. Chemosphere. 99, 152-159. 